Samantha Lemos Turte-Cavadinha ${ }^{1}$

Edu Turte-Cavadinha ${ }^{1}$

Andréa Aparecida da Luz ${ }^{1}$

Frida Marina Fischer ${ }^{2}$

\section{A violência psicológica no trabalho discutida a partir de vivências de adolescentes trabalhadores}

\author{
Workplace psychological violence discussed from teenage \\ workers' experiences
}

${ }^{1}$ Universidade de São Paulo, Faculdade de Saúde Pública, Programa de PósGraduação em Saúde Pública. São Paulo, SP, Brasil.

${ }^{2}$ Universidade de São Paulo, Faculdade de Saúde Pública, Departamento de Saúde Ambiental. São Paulo, SP, Brasil.

Contato

Samantha Lemos Turte-Cavadinha

E-mail

samturte@usp.br

Este trabalho é fruto da Dissertação de Mestrado de Samantha Lemos TurteCavadinha, sob a orientação de Frida Marina Fischer, defendida no Programa de Pós-Graduação em Saúde Pública da Faculdade de Saúde Pública da Universidade de São Paulo, em 2012.

Trabalho apresentado no V Congresso Ibero-Americano de Pesquisa Qualitativa em Saúde, em Lisboa, em 2012 (resumo publicado nos anais) e no 18th World Congress on Ergonomics, em Recife, em 2012 (resumo expandido publicado no periódico Work (Reading, MA), v. 41, p. 5674-5676, 2012).

Apoio: CNPq (Auxílio à Pesquisa processo no 473138/2008-5) e FAPESP (bolsa de mestrado da primeira autora - processo no 2009/12515-0)

Os autores declaram não haver conflitos de interesse.

\section{Resumo}

Objetivo: identificar e discutir situações de trabalho relatadas por adolescentes trabalhadores que pudessem se constituir como violência psicológica no trabalho. Métodos: foram realizadas entrevistas individuais semiestruturadas com 30 jovens trabalhadores entre 15 e 20 anos de idade. As informações foram analisadas a partir da análise hermenêutico-dialética. Resultados: em geral, os participantes perceberam os "relacionamentos interpessoais" no trabalho como bons, mas relataram inúmeras situações de "mal-estar no trabalho" que incluíram humilhações, abusos de poder, constrangimentos e assédio sexual, revelando ocorrências de violência psicológica no trabalho. Os jovens mais empoderados e autônomos conseguiram enfrentar com mais firmeza as situações abusivas, fossem elas por parte de colegas de trabalho ou de superiores hierárquicos. Conclusão: os adolescentes ingressantes no mundo do trabalho estão expostos a situações que ameaçam a saúde mental e se valem, sobretudo, do apoio social como estratégia de enfrentamento. Sugere-se a inclusão de temas de Saúde Mental e Trabalho, não só em organizações de educação para o trabalho, mas também no ensino médio regular, como contribuição ao preparo dos adolescentes e para que possam identificar e desenvolver estratégias de enfrentamento à violência psicológica.

Palavras-chave: saúde do trabalhador; saúde mental; aprendizes e estagiários; violência psicológica; condições de trabalho.

\begin{abstract}
Objective: to identify and discuss work conditions reported by young workers which could be constituted as psychological violence at work. Methods: semi-structured individual interviews were conducted with thirty adolescent workers aged 15 to 20 years old. The data were analyzed using the hermeneutic-dialectic method. Results: overall, participants perceived the "interpersonal relationships" at work as good, but they reported many situations of "malaise at work", which included humiliation, power abuse, embarrassment and sexual harassment, revealing occurrences of psychological violence at work. Youngsters who were more empowered and autonomous were able to deal more firmly with abusive situations, whether they were produced by coworkers or superiors. Conclusion: adolescents entering the labor market are exposed to work conditions that can be harmful to their mental health, and social support is mainly their coping strategy. The mental health and work theme should be included in professional training and high school as a way to contribute to the better preparedness of teenage workers, so that they could identify and develop coping strategies to deal with psychological violence.
\end{abstract}

Keywords: occupational health; mental health; apprentices and trainees; psychological violence; working conditions. 


\section{Introdução}

A violência psicológica refere-se ao uso intencional de poder em qualquer conduta que cause dano emocional e diminuição da autoestima, que prejudique o pleno desenvolvimento ou que vise controlar comportamentos, mediante constrangimento, humilhação, isolamento, vigilância constante, ridicularização ou qualquer outro meio que cause prejuízo à saúde psicológica (BRASIL, 2006). Esse tipo de violência é uma violação real da autonomia, da dignidade e do direito de autodeterminação dos indivíduos que pode ser tão ou mais danosa que a violência física. Manipular, ameaçar, degradar e aterrorizar são mecanismos utilizados para destruir a pessoa vitimada, sendo que os casos mais nocivos são aqueles perpetrados por pessoas em posição de autoridade sobre o atingido (GARVER, 1973). Heloani e Barreto (2010, p. 40) consideram-na "o mais poderoso e destrutivo método de controle”.

Quando a violência psicológica ocorre no ambiente de trabalho torna-se um dos fatores psicossociais que constituem um risco, visível ou invisível, à saúde, provocando mal-estar. A violência no trabalho pode estar contida de forma insidiosa na cultura organizacional, sendo que o indivíduo afetado pode desenvolver inúmeras doenças, inclusive transtornos mentais, havendo alto risco de suicídio para as vítimas (HELOANI; BARRETO, 2010).

A complexidade da violência psicológica exige um olhar aprofundado sobre cenários socioculturais, econômicos e profissionais, a partir dos quais as inter-relações existentes expressam-se em relações de poder que caracterizam a violência psicológica no trabalho; e é a partir da manipulação da afetividade e das emoções que o poder se configura como abuso (CALDAS; NEVES, 2008).

Algumas "expressões" da violência psicológica no trabalho costumam ser apresentadas em estudos sobre o tema como: assédio moral, ameaças, intimidações, abuso de poder, humilhações, discriminações e assédio sexual (JACKSON; ASHLEY, 2005; OLIVEIRA; NUNES, 2008). Tais situações, pontuais ou não (como no caso do assédio moral, que ocorre de forma sistemática), podem se apresentar de forma individual ou em conjunto, compondo um complexo sistema ameaçador à saúde mental. Os episódios de violência no ambiente de trabalho podem também incluir comportamentos não civilizados (workplace incivility) que seriam formas mais leves de maus-tratos, como a falta de respeito com o outro, em que a intenção de causar prejuízo é mais difícil de ser determinada (CORTINA et al., 2001).

A Organização Internacional do Trabalho (OIT) reconhece a dificuldade em precisar um conceito que relacione violência e trabalho, pois sua definição depende de uma grande variedade de comportamentos que podem ou não ser considerados violentos em virtude de diferentes contextos e culturas (INTERNATIONAL LABOUR OFFICE, 2006).

A literatura científica internacional contém inúmeros estudos sobre a ocorrência de violência psicológica em suas diversas formas no ambiente de trabalho (ROSPENDA; RICHMAN; SHANNON, 2009; FRONE, 2000). Silva, Coelho e Caponi (2007) afirmavam existir uma aparente indiferença dos pesquisadores brasileiros em escrever especificamente sobre a violência psicológica, sendo dada prioridade às formas de violência que provocam graves consequências físicas em detrimento das psicológicas. Esse fato explicaria, pelo menos parcialmente, a dificuldade em encontrar referências a este tema em outros âmbitos, que não o da violência doméstica. Nos últimos anos, o tema começou a ganhar relevância no Brasil, sobretudo no meio acadêmico, tendo sido publicados artigos diversos abordando a temática do assédio moral no trabalho, uma das apresentações mais comprovadamente nocivas da violência psicológica. Em geral, os artigos que tratam do assédio moral no trabalho abordam a precarização do trabalho e sua disseminação nas estruturas de gestão organizacional, comprovando a necessidade de ser repensada a lógica que permite, ou ainda incentiva, que o fenômeno ganhe força. $\mathrm{O}$ assédio moral é um evento com características específicas dentro do complexo espectro da violência psicológica, a qual inclui inúmeras situações disseminadas e banalizadas em nossa sociedade, afetando a saúde mental dos trabalhadores cotidianamente. Neste estudo, optamos por abordar aspectos da violência psicológica que abrangem, mas não se restringem ao assédio moral no trabalho, entendendo que a subjetividade dos trabalhadores é também afetada pela qualidade das relações interpessoais, além da configuração organizacional.

Especialmente durante a adolescência, conflitos no trabalho representam um importante estressor ocupacional, pois nesta fase seriam desenvolvidas competências interpessoais, particularmente entre os 16 e 21 anos de idade. Tais conflitos empobrecem os relacionamentos e associam-se à ocorrência de violência psicológica (FRONE, 2000).

É importante identificar e gerenciar as características do trabalho de jovens. As condições de trabalho podem comprometer negativamente as atitudes profissionais e a saúde mental, considerando que adolescentes que ainda estão se desenvolvendo cognitiva, emocional e socialmente podem ter menos recursos para lidar com experiências traumáticas e sofrer efeitos significativos (FRONE, 2000). Em estudo com 1.400 adolescentes trabalhadores norte-americanos com idade entre $14 \mathrm{e}$ 17 anos, Rauscher (2008) verificou que aproximadamente $25 \%$ haviam sofrido ameaças verbais e $10 \%$ haviam sido assediados sexualmente. Outros estudos confirmaram 
que, além de características específicas da adolescência, a pressão no trabalho e constrangimentos psicossociais tornam os jovens mais suscetíveis ao desenvolvimento de doenças relacionadas ao trabalho (FISCHER et al., 2003).

A revisão de literatura sem delimitação temporal nas principais bases de dados, Scielo, Medline, Bireme e Lilacs, não mostrou estudos brasileiros que tenham sido realizados com adolescentes trabalhadores abordando a temática da violência psicológica no trabalho. $\mathrm{O}$ foco das discussões da violência psicológica no trabalho no Brasil geralmente se concentra no tema do assédio moral e organizacional. São frequentes os discursos e publicações sobre a gestão organizacional propiciando este tipo de violência (GOSDAL; SOBOLL, 2009). Entretanto, verifica-se uma lacuna no conhecimento ao se buscarem estudos cuja preocupação seja dirigida a adolescentes aprendizes e estagiários, que apresentam peculiaridades em sua inserção no mundo de trabalho.

Há um numeroso contingente de adolescentes no mundo inseridos no mercado de trabalho. $\mathrm{Na}$ América Latina, existem 12,6 milhões de jovens estudantes trabalhadores (INTERNATIONAL LABOUR ORGANIZATION, 2010). No Brasil são cerca de 18,2 milhões de jovens inseridos no mundo do trabalho (incluídos os que apenas trabalham e os que trabalham e estudam) dentre os 34 milhões de jovens brasileiros entre 15 e 24 anos (ORGANIZAÇÃO INTERNACIONAL DO TRABALHO, 2009). Acredita-se que o maior número de jovens que ingressam precocemente no trabalho sejam filhos de trabalhadores que residem em bairros populares ou favelas das médias e grandes cidades do Brasil (FRIGOTTO, 2004). Esses jovens costumam pertencer à classe ou à fração de classe "filhos de trabalhadores assalariados", conforme aponta Frigotto (2004), isto é, que produzem a vida, a partir de uma inserção no mercado de trabalho. Esta não seria uma escolha, mas uma imposição de sua origem social e do tipo de sociedade que se construiu no Brasil. É o que este autor entende como um processo de "adultização precoce”, com uma inserção precária, em termos de condições e níveis de remuneração, no mercado formal ou "informal" de trabalho. Diferentemente, a grande maioria dos jovens de "classe média", ou filhos dos donos de meios de produção, inicia sua inserção no mundo do trabalho após os 25 anos e em postos de trabalhos ou atividades de melhor remuneração. Os adolescentes trabalhadores seriam, assim, potencialmente mais vulneráveis à violência psicológica no trabalho por sua precocidade e imaturidade ao iniciarem a vida profissional, seja por sofrerem efeitos nocivos adicionais, seja por aprenderem a banalizá-la e reproduzi-la. Diante desse panorama, há pertinência em abordar a temática da violência psicológica nesse grupo etário. Destarte, o objetivo do estudo foi identificar e discutir situações de trabalho relatadas por jovens trabalhadores que possam se constituir em violência psicológica no trabalho.

\section{Procedimentos metodológicos}

Buscar compreender as situações vividas e como são as relações interpessoais vivenciadas pelos adolescentes no ambiente de trabalho é tarefa que exige subsídios que privilegiem o diálogo como fonte de informação. A pesquisa qualitativa pode oferecer formas diferentes e inovadoras de produzir dados (DENZIN; LINCOLN, 2000), pois há uma diversidade de estratégias que, muitas vezes, conseguem ir até onde a pesquisa quantitativa não consegue chegar. Neste trabalho, a estratégia escolhida foi a análise hermenêutico-dialética proposta por Minayo (2008), que norteou todas as etapas da pesquisa. Essa análise permite uma reflexão que se funda na práxis, através de um processo ao mesmo tempo compreensivo e crítico de estudo da realidade social. Sendo assim, a análise hermenêutico-dialética considera que é necessário explicitar o contexto no qual determinado texto foi produzido para que se possa compreender a totalidade dinâmica das relações sociais de produção e reprodução nas quais está inserido. A união da hermenêutica com a dialética leva o intérprete a entender a fala, tanto como resultado de um processo social quanto de um processo de conhecimento, ambos resultantes de múltiplas determinações, que adquirem significados específicos (MINAYO, 2008).

A análise hermenêutico-dialética utiliza níveis diversos de categorias em seu processo de compreensão. Minayo (2008 , p. 178), partindo de Marx (em Introdução à Crítica da Economia Política, 1973), esclarece que, por categorias, entende “[...] conceitos relevantes carregados de sentido que permitem expressar os aspectos fundamentais das relações dos seres humanos entre si e com a natureza”. Laperrière (2008) relembra que é essencial que a categoria constitua uma dimensão pertinente do fenômeno observado. O pesquisador deve detalhar o conteúdo das categorias através de dois movimentos: primeiramente, deve minimizar as diferenças observadas, de modo a detalhar e consolidar o conteúdo das categorias; e, num segundo momento, deve maximizar as diferenças, para apreender as condições de surgimento e de variação do fenômeno pesquisado.

Para a construção do roteiro de entrevista semiestruturada, foram utilizadas categorias operacionais (MINAYO, 2008). As categorias que nortearam a construção do roteiro foram: trabalhar na adolescência, violência psicológica no trabalho, relacionamentos interpessoais e apoio social. Cada categoria abarcava questões abertas para que se pudessem sondar as vivências dos jovens no ambiente de trabalho. 
O estudo foi realizado em uma Organização Não Governamental (ONG) localizada na zona sul da cidade de São Paulo. Essa ONG tinha por base um trabalho educativo que proporciona aos adolescentes de baixa renda condições para concorrer a uma vaga no mercado de trabalho e a possibilidade de adquirir conhecimentos a respeito de seus direitos como cidadãos e deveres de convivência na sociedade.

Os jovens que ingressavam no programa dessa ONG passavam por um curso de preparação para o trabalho e depois eram encaminhados para empresas, podendo na época ser contratados por até dois anos como aprendizes ou estagiários. Uma vez contratados, além das atividades laborais, os jovens também frequentavam os programas de Estágio ou de Aprendizagem na ONG, onde tinham um acompanhamento mensal (estagiários) ou semanal (aprendizes), durante o tempo de contrato, de forma a complementar sua formação de trabalhador e discutir questões surgidas na vivência cotidiana do trabalho.

A pesquisa foi apresentada primeiramente à diretoria da ONG, momento em que foi solicitada a autorização para a realização do estudo. Em seguida, o estudo foi apresentado ao coordenador pedagógico, aos professores e aos alunos da ONG. Como critério de inclusão da pesquisa, foram convidados estudantes trabalhadores de ambos os sexos que faziam parte dos programas de Estágio ou de Aprendizagem há pelo menos seis meses, para que já tivessem algum tempo de contato com o ambiente profissional. Os dois grupos de jovens possuíam contrato especial de trabalho ajustado por prazo determinado, conforme legislação Lei ㄲo. 10.097 para os aprendizes (BRASIL, 2000) e Lei o․ 8.069 Artigo 68 para os estagiários (BRASIL, 1990). O tempo máximo de contrato de trabalho nesse regime era de 24 meses. Trinta jovens que tinham entre 15 e 20 anos aceitaram voluntariamente participar da pesquisa, sendo 19 homens e 11 mulheres. A composição dos dois grupos participantes contemplou vários períodos de contrato de trabalho. Dezoito jovens entrevistados trabalhavam há menos de 12 meses. Os que trabalhavam há mais tempo ( 2 jovens), estavam contratados há 21 meses.

Todos eles estudavam durante o período noturno - ensino médio (21), técnico (3) ou superior (6) e trabalhavam em diferentes empresas e setores (Indústria, Comércio ou Serviços) durante o período diurno, atuando nas áreas administrativa, financeira ou comercial. De acordo com os dados referidos pelos aprendizes e estagiários, todos os participantes residiam em bairros periféricos da região metropolitana de São Paulo, com prevalência da população de baixa renda e ganhavam 1 salário mínimo. Em relação à renda familiar, quase metade do total de jovens aprendizes e estagiários possuía renda entre 1 e 3 salários-mínimos.

A obtenção dos relatos foi realizada entre novembro e dezembro de 2009. As entrevistas individuais tiveram duração aproximada de 30 minutos. No início de cada entrevista, o participante era questionado sobre idade, sexo, escolaridade, salário e renda familiar, tempo na ocupação, função e atividades realizadas, jornada diária e semanal de trabalho. As entrevistas foram gravadas e transcritas integralmente. Primeiramente, através de leituras, foram anotadas lateralmente nas transcrições as primeiras impressões sobre os assuntos surgidos nas entrevistas e destacados os trechos que continham ideias centrais e relevantes.

No segundo momento, foi feita uma divisão em subconjuntos com base nas questões de entrevista e em conjuntos maiores de acordo com o assunto (por exemplo, o conjunto 'realidade no trabalho' continha os subconjuntos 'relacionamentos interpessoais e situações abusivas'; 'prevenção e formas de enfrentamento'). Após diversas leituras transversais de cada subconjunto e do conjunto em sua totalidade, foram construídos temas reunindo os trechos das falas dos jovens. Do agrupamento desses temas, foram constituídas as categorias empíricas (MINAYO, 2008) que contêm e expressam relações e representações específicas do grupo estudado.

Os temas "bons relacionamentos com apoio social no trabalho"; "relacionamentos instáveis e sem apoio social" foram contemplados na categoria empírica "relacionamentos interpessoais". Os temas "humilhação"; "abuso de poder"; "constrangimentos" e "assédio sexual" deram origem à categoria "mal-estar no trabalho". Por fim, as interpretações dos participantes foram fundidas com as nossas interpretações, considerando o diálogo com a literatura vigente sobre a temática. Embora tenham sido entrevistados jovens originários de diferentes programas, Estágio e Aprendizagem, as vivências demonstraram ser muito semelhantes, motivo pelo qual foram realizadas a análise e a discussão conjunta dos dados.

Cabe ressaltar que o trabalho foi submetido e aprovado pelo Comitê de Ética em Pesquisa da Faculdade de Saúde Pública da Universidade de São Paulo (COEP/FSP) sob o no 2021/2009. Foi realizada a explanação da pesquisa para cada um dos jovens e feita a entrega e leitura do Termo de Consentimento Livre e Esclarecido (TCLE). Os jovens menores de 18 anos de idade foram orientados a entregar o documento para os pais ou responsável legal para que autorizassem sua participação no estudo.

\section{Análise e discussão dos resultados}

\section{Relacionamentos interpessoais no trabalho}

Em geral, os participantes percebiam os relacionamentos interpessoais no ambiente de trabalho como bons. Foram diversas as falas ressaltando a satisfação relacionada à boa convivência pessoal e 
profissional no trabalho, assim como apoio social recebido tanto de colegas de trabalho quanto por parte da chefia. O apoio social é um dispositivo de ajuda mútua, com aspectos como compartilhamento de informações, auxílio em momentos de crise e influência positiva sobre a saúde contra situações de estresse ao criar uma sensação de coerência e controle da vida (ANDRADE; VAITSMAN, 2002). De acordo com Antunes e Fontaine (1996), o apoio social é configurado nas diferentes funções que pessoas significativas ou grupos desempenham para um indivíduo estabelecendo uma rede de relações sociais, a qual permite ao indivíduo sentir-se estimado e confiante de que terá auxílio, conforto e compreensão quando necessitar. Os autores acreditam que jovens tendem a procurar amigos com mais frequência do que familiares em tais situações. Seguem abaixo falas de jovens entrevistados a respeito do apoio que recebem no trabalho:

Pessoal muito legal, mesmo. [...] Se você tem alguma dúvida, mesmo se ele não é do seu departamento, e ele sabe te ajudar, ele vai te ajudar, sem problema. Eu me dou muito bem com o pessoal também, todo mundo brinca, todo mundo trabalha junto, pra manter a empresa bem legal. (estagiário, 17 anos, sexo masculino)

Eu fui bem recebido, lá tem pessoas que confiam no meu potencial e isso ajuda muito, isso é uma força muito grande pra mim. Porque tem empresas que não acreditam no aprendiz, acham que o cara vai lá só pra bagunçar. E o meu gestor ele me ajuda em algumas coisas, não só como chefe, mas às vezes como um amigo também. (aprendiz, 17 anos, sexo masculino)

Alguns entrevistados, no entanto, informaram viver relacionamentos interpessoais instáveis e sem apoio social da parte de colegas ou da chefia. Os relacionamentos interpessoais influenciam no cotidiano de forma significativa, seja através da formação de relações harmoniosas que propiciam o aperfeiçoamento e crescimento pessoal dos envolvidos ou através de relações desfavoráveis, tensas, que, além de provocar danos emocionais, podem dificultar o desenvolvimento e a realização das atividades na equipe (WAGNER et al., 2009).

Atualmente, [com] minha chefia não está bom, mas também não está ruim. Está razoável, tem dias que está péssimo, mas tem dias que está bom. Parece um mar, vai pra lá e vem pra cá, não está estável. (aprendiz, 20 anos, sexo masculino)

[...] Com a minha coordenadora, não é assim. Ela tem dias que ela está bem, tem dias que ela está mal e o dia que ela está mal, ela desconta em você. E esse fato acaba afetando sua vida profissional. [...] eu tenho essas desavenças com ela. E isso acaba afetando muito. (estagiário, 15 anos, sexo masculino)

Quando o indivíduo percebe de forma acurada uma situação e suas variáveis, ele desempenha melhor o seu trabalho, além de ser mais capaz de se posicionar de forma habilidosa na rede de relações interpessoais no local de trabalho, tanto com clientes quanto com outros trabalhadores da empresa (RODRIGUES; IMAI; FERREIRA, 2001). Alguns adolescentes entrevistados afirmaram preferir manter um relacionamento estritamente profissional, ainda que seja dada abertura para a informalidade no tratamento. Outros ficavam um pouco desconfortáveis com a situação de formalidade e relataram não saber lidar bem com a diferença de situação dentro e fora do ambiente de trabalho. De uma forma ou de outra, esses jovens demonstraram não conseguir harmonizar de forma satisfatória o campo profissional e pessoal; sentiam-se desconfortáveis por encontrar uma realidade diferente da que esperavam e revelam sua imaturidade no manejo das relações interpessoais nos diferentes contextos.

\begin{abstract}
Meu chefe, ele é bem sério. [...] Quando ele chega no serviço, é ele fechado nele, fazendo as coisas dele. Mas fora, ele chega pra conversar com a gente, só que, como a gente está acostumado com aquele jeito sério, fechado, de ser, a gente não sabe como conversar com uma pessoa assim. (aprendiz, 17 anos, sexo feminino)

[...] eu evito conversa até por respeito, porque lá é assim, eles dão muita abertura e muita gente acaba se excedendo, mesmo que esteja no nível que eles permitem, mas eu já não gosto muito disso, sempre procurei ficar na minha [...] (aprendiz, 18 anos, sexo masculino)
\end{abstract}

A qualidade do apoio social recebido é um importante fator que interfere no enfrentamento da violência psicológica no trabalho e pode ser determinante para minorar ou agravar os efeitos nocivos à saúde mental dos envolvidos. Apesar da maioria dos jovens afirmar perceber a vivência dos relacionamentos no trabalho como boa, no decorrer das entrevistas foram relatadas inúmeras situações que geravam mal-estar e que podem ser expressões de violência psicológica no trabalho.

\section{Mal-estar no trabalho}

Foram classificados na categoria "mal-estar no trabalho" relatos dos participantes a respeito de situações de humilhação, abuso de poder, constrangimentos e assédio sexual. Esses temas surgiram em momentos diversos das entrevistas, relatando situações vividas ou presenciadas pelos jovens. As situações foram relatadas por jovens com diferentes tempos de experiência, de empresas diversas e que trabalhavam em diferentes setores, não sendo neste estudo percebida maior recorrência associada a determinado tipo de ramo empregatício ou tempo de vinculação à empresa.

Entre as situações de humilhação sofridas pelos jovens no ambiente de trabalho, destacam-se as agressões verbais, as quais geralmente são aplicadas como forma de punição, para corrigir algum erro 
realizado pelo profissional ou recriminando uma situação, conforme exemplificado nas falas abaixo:

Foi um fato de eu ter feito algum serviço errado e ter sido chamado de ignorante, de burro, agressividades assim, em geral. (aprendiz, 20 anos, sexo masculino)

[...] Eu tinha um problema no braço. [...] eu não era acostumado a trabalhar e lá, às vezes, a gente carregava um pouco de peso, trabalhava com correio, trabalhava com caixas grandes. E aí, teve uma época que eu não conseguia carregar peso, não conseguia escrever, não conseguia digitar. E aí eu acabei ouvindo coisas que me desagradaram profundamente. (aprendiz, 17 anos, sexo masculino)

[...] eu trabalho em uma central de atendimento e é como se fosse uma ouvidoria. Lá dá muito, muito problema. Então já me senti muito desrespeitada, sim. [...] mas a gente tem que entender que o cliente está xingando e desrespeitando a empresa. Não você, não o funcionário. Mas tem certas coisas que alguns clientes falam que, realmente, você se sente machucado, se sente magoado pelo que falou. (aprendiz, 17 anos, sexo feminino)

As humilhações e depreciações constantes caracterizam a violência psicológica e podem resultar em danos para os adolescentes ao minar-lhes a autoestima e a segurança (SAITO, 2010). Barreto (2003) afirma que, nas relações autoritárias, a saúde pode ser abalada, havendo manifestações de distúrbios psíquicos que podem alterar as condutas daqueles que não são reconhecidos como sujeitos. Essa forma de violência, como pode ser considerada a humilhação inerente às situações descritas, é um importante indicador da qualidade das condições de trabalho (OLIVEIRA; NUNES, 2008). Gaulejac (2007) discute os efeitos dos modos de gerenciamento na produção de sofrimento psíquico e de problemas relacionais entre os trabalhadores da empresa que, submetidos à intensa pressão, por não poderem intervir sobre as faltas cometidas pela organização do trabalho, acabam por se agredirem mutuamente. Essa reflexão do autor é extremamente pertinente e, embora não seja objeto deste trabalho aprofundar essa discussão, existem inúmeros artigos que investigam a estreita vinculação entre as condições de trabalho decorrentes das políticas de gestão e a ocorrência de assédio no trabalho (HELOANI, 2005; GOSDAL; SOBOLL, 2009).

Atritos com a chefia também são frequentes, especialmente relacionados a situações de abuso de poder, geralmente em solicitações que contemplam desvio de função para realizar atividades perigosas ou tarefas que, por lei, não podem ser realizadas por jovens trabalhadores e menores de 18 anos (BRASIL, 1990). Alguns jovens confrontaram os chefes demonstrando que conheciam a lei e que não poderiam realizar funções diferentes daquelas constantes no contrato de trabalho. Nas situações relatadas abaixo, tem-se dois exemplos: no primeiro, o jovem não aceitou executar a tarefa solicitada por conhecer a lei de que um adolescente não pode realizar trabalhos que representem risco à sua saúde; no segundo, a jovem acabou por se submeter à situação por não saber como enfrentá-la.

Conheço só algumas leis: a lei que um aprendiz não pode correr riscos. E meu chefe pediu pra eu transportar algumas peças para outra caçamba. [...] E eu falei: "não vou fazer, porque na minha carteira está que eu sou um aprendiz administrativo, não ajudante geral". E ele: "você tem que fazer, você é meu funcionário". [...] E certamente eu não fiz, ele ficou meio bravo, a gente praticamente ficou uma semana sem falar um com o outro. (aprendiz, 20 anos, sexo masculino)

Quando procuram que eu faça o serviço do "office boy" [...] Eu sei que aquele não é o meu serviço e que está no contrato que não pode. Mas eu acho que não é viável falar não. [...] Aí eu me sinto meio que constrangida, porque eu sei que não posso. (estagiário, 15 anos, sexo feminino)

Estes relatos revelaram que os adolescentes estavam expostos a situações de abuso de poder e que conhecer a lei não era garantia de proteção, pois enfrentar uma situação abusiva cometida por um superior hierárquico remete à possibilidade de punição ou demissão. Contudo, ainda assim, o conhecimento a respeito de direitos e deveres pode ser um meio de evitar ou contornar situações claras de exploração.

As relações de poder refletidas nas interações interpessoais no trabalho envolvendo os jovens entrevistados constroem-se e revelam-se nas desigualdades socioeconômicas e hierárquicas dos envolvidos. Superiores hierárquicos e colegas de trabalho julgam-se detentores de um saber e um poder que não é possibilitado aos jovens trabalhadores com pouco tempo de experiência profissional e ainda em formação educacional. McLaughlin, Uggen e Blackstone (2008) destacam que a origem social pode afetar a quantidade, qualidade e tipo de trabalho e, portanto, a exposição dos trabalhadores a situações de assédio. Sendo assim, jovens trabalhadores de classes baixas podem ser especialmente vulneráveis à violência psicológica no trabalho.

Em virtude de sua condição socioeconômica e cultural, segundo Asmus et al. (2005), os jovens se afastam da compreensão do significado social do trabalho e dos fatores psicossociais do trabalho associados ao adoecimento. Os autores relembram que a experiência do trabalho precoce entre as classes populares tem reflexos mascarados na saúde dos jovens, pois as doenças do trabalho geralmente aparecem somente na fase adulta. Esses fatos dificultam o desenvolvimento de políticas de proteção ao trabalho do adolescente. 
Neste estudo, a condição socioeconômica dos jovens entrevistados, originários de famílias de baixa renda e pouca escolaridade, afetara também as relações interpessoais no ambiente de trabalho, conforme demonstram os relatos, como queixas por parte dos jovens sobre insinuações implícitas e explícitas de que eles poderiam ser responsáveis por roubos (de alimentos e dinheiro) no ambiente de trabalho.

Teve uma época na minha empresa que estava sumindo coisas da copa. [...] Aí chegou lá um funcionário reclamando que tinham comido coisa da geladeira que era dele [...] ele falou com a intenção de que eu me sentisse culpada, entendeu? Aí eu senti isso da parte dele. Eu achei isso muito desrespeitoso. (estagiário, 15 anos, sexo feminino)

Outras situações relativas à condição social e hierárquica dos jovens dentro da empresa foram citadas, as quais, inclusive, colocavam em xeque a sua capacidade de aprender, de desempenharem bem seu trabalho e crescerem profissionalmente.

Um estagiário de faculdade fez um comentário maldoso [...] e eu achei desrespeitoso. Há pessoas que, infelizmente, tentam ser melhor do que as outras por estar fazendo uma faculdade. (estagiário, 18 anos, sexo masculino)

Nesse relato, o estagiário da faculdade se sentiu no direito de afirmar sua superioridade, dada sua condição de "fazer faculdade". A desqualificação, neste caso, não apareceu apenas por uma condição presente, mas como se houvesse a impossibilidade do adolescente vir a ser igual em condições de acesso ao ensino superior ou de ocupar a mesma vaga profissional. Neste exemplo, à violência psicológica soma-se o sofrimento ético-político, conforme definido por Sawaia (2001, p. 105), que retrata a

[...] vivência cotidiana das questões sociais dominantes em cada época histórica, especialmente a dor que surge da situação social de ser tratado como inferior, subalterno, sem valor, apêndice inútil da sociedade.

Chaui (1998) considera que a forma como a sociedade brasileira se estrutura não só permite como propicia que esse tipo de exclusão seja legitimado e não seja, portanto, tomado como forma de violência.

Segundo McLaughlin, Uggen e Blackstone (2008), para os adolescentes pobres ou da classe trabalhadora que são obrigados a trabalhar por razões financeiras, a violência psicológica no trabalho pode ter efeitos negativos de longo prazo sobre o nível socioeconômico. Os jovens trabalhadores que experimentam assédio podem também desenvolver expectativas negativas sobre os empregos futuros, sofrer consequências monetárias e terem a si negada valiosa experiência de trabalho para se prepararem para futuras carreiras.

Quando não há o reconhecimento da necessidade de aprendizado que a colocação lhes deveria possibilitar, esses jovens passam a ser reprodutores de tarefas simples que não lhes permitem aprender com o trabalho.

É pra falar a verdade, eu não tenho tantas expectativas no meu trabalho hoje, porque onde eu trabalho é tudo muito fechado. Cada um é muito egoísta no que faz. [...] Quando uma pessoa falta, acabou o mundo. Ninguém sabe fazer nada. [...] Eu até tentei, eu juro que tentei saber um pouquinho de cada coisa, mas o pessoal não deixa. (estagiário, 16 anos, sexo feminino)

Sawaia (2001, p. 9) relembra que inclusão e exclusão representam um continuum dialético em que se apresentam nuances de diferentes qualidades e dimensões. Incluem-se aí, segundo a autora, a dimensão objetiva da desigualdade social, a dimensão ética da injustiça e a dimensão subjetiva do sofrimento. Essas seriam faces de uma exclusão que pode se manifestar em "inclusão social perversa", a partir da qual a sociedade cria uma ilusão de inclusão que determinaria um distanciamento do sujeito da possibilidade de ser igual ao "nós que o exclui, gerando o sentimento de culpa individual pela exclusão", porquanto, ao mesmo tempo em que estes jovens são incluídos no mercado de trabalho, eles muitas vezes são discriminados por serem aprendizes ou estagiários.

Os jovens trabalhadores inseridos precocemente no mercado de trabalho podem estar sujeitos a esta forma de inclusão ilusória com efeitos deletérios. Seja pelas condições precárias encontradas, na ausência de trabalho decente, ou pelos efeitos nocivos que essa inserção precoce pode ter sobre a formação e saúde dos jovens, quando a empresa não cumpre a função educativa a que se propõe, ela atua como "[...] instrumento de legitimação para a manutenção e reprodução social da pobreza e da estrutura ocupacional" (MINAYO-GOMEZ; MEIRELLES, 1997, p. 138). Os autores citados afirmam ainda que o trabalho de adolescentes

[...] acaba por lhes impor um c usto social elevado: a renúncia a um grau de escolarização maior, capaz de lhes garantir, no futuro, melhor colocação no mercado de trabalho; ou uma sobrecarga de tarefas da qual resulta considerável desgaste físico e mental, pois a atividade laborativa é uma fonte de estresse emocional de origem social na infância e adolescência. (MINAYOGOMEZ; MEIRELLES, 1997, p. 138)

Se, por um lado, as citações apresentadas podem ser exemplos da inclusão perversa, conforme discutida por Sawaia (2001) e Minayo-Gomez e Meirelles (1997), por outro, elas refletem no destaque a seguir, a respeito do não reconhecimento, reclamação apresentada por vários jovens trabalhadores entrevistados. Não há um reconhecimento por muitos colegas e por muitos superiores hierárquicos do momento de aprendizado que deveriam estar vivendo esses jovens na empresa. Essa falta de reconhecimento, além de afetar o 
aprendizado, pode igualmente afetar o bem-estar psicológico desses jovens.

Siqueira e Padovam (2008) entendem que o bemestar psicológico consiste no funcionamento pleno das potencialidades de uma pessoa, traduzidas em capacidade de pensar, usando raciocínio e bom senso. Além disso, outras dimensões seriam associadas ao bem-estar: autoaceitação, relacionamento positivo com outras pessoas, autonomia, propósito de vida e crescimento pessoal. Seja quando há uma repreensão exagerada por um erro cometido, seja na desconfiança sentida pelos entrevistados sobre sua capacidade profissional, ou ainda quando sua opinião sobre o próprio trabalho não é ouvida, eles querem ser "pessoas" e não somente aprendizes ou estagiários. Ao se utilizar da expressão "passar a ser uma pessoa e não um aprendiz", o jovem revela o sentimento de desmerecimento da figura do aprendiz em relação aos outros profissionais da empresa, com menos direitos e, inclusive, menos voz que uma pessoa (profissional) reconhecida como tal tem ou deveria ter. Essa é a insatisfação que repetidas vezes os jovens entrevistados por este estudo demonstraram. Incomoda, e muito, o fato do aprendiz ser "menos" em relação aos outros, de ter um lugar "menor" na empresa e, principalmente, de não ser ensinado a ser profissional como esperavam que fosse. $\mathrm{Ou}$, como diz Sawaia (2001, p. 115), a enunciação do desejo de "ser gente" não diz respeito apenas ao "[...] desejo de igualar-se, mas de distinguir-se e ser reconhecido."

Crescimento. Crescer, passar a ser uma pessoa, e não um aprendiz. [...] o menor aprendiz é meio que excluído em alguns assuntos, sendo que participa. Então você tem que correr atrás, você tem que saber. (aprendiz, 16 anos, sexo masculino)

Eu não sei se é pelo nome aprendiz, se aprendiz não tem experiência, eu até concordo, porque muitas coisas precisam ser conferidas, só que tem sempre a desconfiança. [...] É como se você não pudesse errar, como se você fosse uma máquina, um robozinho, que não pudesse errar em algumas coisas. Coisas que gestores mesmo erram. (aprendiz, 16 anos, sexo feminino)

E a falta de reconhecimento pode ter um efeito desastroso sobre aqueles que entraram no trabalho com tantas expectativas. A frustração, a desmotivação, os conflitos interpessoais podem surgir e levar o jovem trabalhador a perder a confiança no trabalho ou, inclusive, em si mesmo, em seu potencial criativo.

Ultimamente, nesse trabalho que eu estou agora, eu estou desmotivado. Então, eu não estou conseguindo conciliar meu trabalho, eu estou tendo dificuldades. [...] eu não estou confiando muito bem no trabalho. As minhas expectativas eram ter um cargo efetivo, crescer dentro da empresa e ser um ótimo profissional. Hoje, não mais. (aprendiz, 20 anos, sexo masculino)
É difícil levantar pra todo dia ter que ir trabalhar, porque eu já estou meio desgastado com o ambiente, por causa de algumas coisas que eu já ouvi falarem, de algumas coisas que estão mudando lá dentro. E parece que eles não dão importância pra gente, pros funcionários. (aprendiz, 16 anos, sexo masculino)

Em relação ao aprendiz fica um clima chato toda terça escutar: "ah, vai lá, passear, ficar brincando”. Nunca é levada a sério a questão do aprendiz. (aprendiz, 17 anos, sexo feminino)

Brincadeiras no ambiente de trabalho também apareceram em diversas falas dos adolescentes, inclusive criando constrangimentos. Ser coagido a aceitar e gostar das brincadeiras, fazer de conta que não é atingido mesmo quando a brincadeira é vexatória são maneiras encontradas pelos jovens para se adaptarem ao ambiente de trabalho que de outra forma seria causador de mal-estar cotidiano. Nesse sentido, Saito (2010) destaca o importante aspecto que a influência do grupo pode ter sobre os adolescentes na deflagração da violência. A autora destaca sobre essa influência que: "[...] se por um lado pode trazer vivências de lideranças e valorização do trabalho em equipe, por outro pode encorajar práticas antissociais ou mesmo violentas que não seriam realizadas por um indivíduo único." (SAITO, 2010, p. 152)

[...] me mudaram de mesa e eu estou sentado aqui de costas pra porta. E todo mundo que passa, vai ali e dá um tapinha nas minhas costas, só que não é um tapinha, é um tapa [com ênfase]. Eu já falei que eu não gosto disso, mas o pessoal lá não respeita muito e eu já saí com "mor" dor nas costas por causa disso. (aprendiz, 17 anos, sexo masculino)

[...] tinha um outro aprendiz, eu andava demais com ele, ele era muito meu amigo. [...] o pessoal falava que eu tinha um "casinho" com ele [...] Aí ficavam tirando foto, escrevendo coisa... [...] Uma vez, teve uma festa de casamento e que fui eu, aquele meu amigo, o pessoal todo. E tipo, esse meu amigo, ele já tinha mais de 18 anos, então ele bebia e tal. [...] Aí, ele já estava com umas caras assim meio de bêbado e foram e tiraram uma foto, e está tipo eu abaixado assim e ele em pé. E aí, essa foto ficou em alguns computadores da empresa, ficaram enviando essa foto. (aprendiz, 17 anos, sexo masculino)

As brincadeiras no ambiente de trabalho podem ser consideradas violentas quando incluem maustratos verbais ou físicos, contêm palavras de agressão em tratamentos "aparentemente amistosos" que mobilizam risos e piadas no ambiente de trabalho (MARTINS; ROCHA; NASCIMENTO, 2009). Essas brincadeiras, também chamadas de "perversas" por Saladini (2007), correspondem a ironias, zombaria, sarcasmo e atitudes vexatórias, com conteúdos de humilhação e desmerecimento.

Outra situação surgida nas entrevistas foi o assédio sexual, que pode ser considerado uma forma de 
violência psicológica. O assédio sexual relaciona-se ao assédio moral, sendo frequentes os casos em que há precedência de um sobre o outro (FREITAS; HELOANI; BARRETO, 2008). A crença de que o assédio sexual só aconteça com mulheres e de que seja comum, faz com que alguns jovens, principalmente do sexo masculino, afirmem "não ser nada demais" e sintam estar livres desse tipo de situação, como relatado por um jovem que banaliza as situações de provocações e insinuações sexuais:

As mulheres passam, alguns tentam mexer, e outros já colocam a cabeça no lugar "para, a mulher é casada” ou "a mulher está aí para trabalhar e você mexendo com ela”. Mas nada demais. (aprendiz, 20 anos, sexo masculino)

A banalização da violência psicológica contida no assédio sexual por homens jovens é reflexo do machismo na sociedade brasileira e permite que a mulher continue sendo objeto deste tipo de atenção sexual, além de dificultar a implementação de medidas de prevenção nos ambientes de trabalho. Uma jovem relatou ter vivido em seu emprego anterior uma situação de assédio sexual. Mesmo após conversar com chefia e agressor, a situação não foi resolvida. Então, a pedido dela, a ONG conseguiu transferi-la para outra empresa, porém não houve em nenhum momento um posicionamento claro da empresa com relação à situação e nenhum tipo de consequência ao perpetrador do assédio.

Foi uma agressão sexual por uma pessoa que dava em cima de mim e falava esses termos de assédio sexual, desenhava e falava pra mim que queria fazer essas coisas comigo. Eu conversei direitinho com a pessoa. Mas aí me afastaram. E a situação não parou, continuava a acontecer e aí eu saí. (estagiário, 20 anos, sexo feminino)

Os jovens trabalhadores queixam-se com mais frequência do que os outros trabalhadores de terem sido objeto de atenção sexual indesejada, constatando-se que as jovens com empregos precários em hotéis e empresas prestadoras de serviços têm muito mais probabilidades de exposição a assédio sexual (AGÊNCIA EUROPÉIA PARA A SEGURANÇA E A SAÚDE NO TRABALHO, 2006). Mesmo não tendo aparecido nas entrevistas, alguns autores como Freitas, Heloani e Barreto (2008) destacam que pesquisas têm revelado que apesar de serem casos raros, o assédio sexual tem se tornado mais frequente tendo o agressor do sexo feminino e um alvo do sexo masculino e ainda situações em que tanto o agressor quanto o agredido são do mesmo sexo. Fineran (2002), em estudo sobre assédio sexual a adolescentes que estudavam e trabalhavam em tempo parcial, percebeu que enquanto garotas tendem a ser assediadas por homens, os garotos costumam ser alvo tanto de mulheres quanto de homens. A partir desse estudo realizado com 712 adolescentes com idade entre
14 e 19, a autora concluiu que 35\% dos participantes já haviam sido assediados sexualmente no trabalho.

[...] foi na Páscoa mesmo e saiu o amigo chocolate e tal, no caso o chefe da menina começou entregar algumas coisas assim... vamos dizer obscenas de chocolate [...] no momento levou na brincadeira, só que ela falou que depois ela acabou refletindo, viu que ele estava no caso com outras intenções também. (aprendiz, 18 anos, sexo masculino)

Ressalta-se ainda que, segundo Fineran (2002), ser assediado sexualmente no primeiro emprego pode ter efeitos negativos sobre a autoestima e identidade em formação dos adolescentes. Essa autora concluiu também que jovens do sexo feminino e do sexo masculino têm diferentes percepções e emoções resultantes do assédio sexual, embora para ambos seja igualmente perturbador e nocivo à saúde.

\section{Enfrentando a violência psicológica no trabalho}

Lunardi Filho, Lunardi e Spricigo (2001) alertam que a atividade profissional é uma forma de inserção social, em que aspectos psíquicos e físicos estão fortemente implicados. Portanto, um trabalho "ideal” seria aquele capaz de satisfazer um grande número de funções vitais ao bem-estar psicológico e motivação dos indivíduos, em que os relacionamentos interpessoais fossem prazerosos e fontes de apoio. Contudo, quando o trabalho tem condições restritivas pode-se esperar um perigoso efeito negativo sobre a identidade, a saúde mental e a qualidade de vida dos indivíduos (TOLFO; PICCININI, 2007).

No presente estudo os relatos dos adolescentes trabalhadores apresentaram indícios de situações de violência psicológica. Foi possível perceber que muitas das situações relatadas são banalizadas e consideradas como naturais às relações interpessoais, entretanto tais situações representam um empobrecimento dos relacionamentos, acarretando danos à formação de laços de apoio social. De acordo com Hirigoyen (2006), a violência psicológica no trabalho seria reflexo do fim da comunicação e do sentimento de superioridade entre as pessoas na sociedade contemporânea. Segundo a autora, não existe mais curiosidade nas trocas com o outro, pois as pessoas já pensariam a priori que o outro nada tem a lhes acrescentar. E continua, alertando sobre a importância do verdadeiro diálogo: “[...] para que exista diálogo, é preciso que exista uma relação entre duas pessoas que se considerem iguais em importância do ponto de vista humano, mesmo que sejam de nível hierárquico diferente.” (HIRIGOYEN, 2006, p. 42)

Os jovens trabalhadores entrevistados acreditam que o enfrentamento à violência psicológica no trabalho seria mais efetivo se algumas ações partissem 
da empresa. Entre as sugestões estão reuniões ou palestras, treinamentos, criação de normas e de um canal de denúncias anônimas, mas sobretudo diálogos. Esta foi uma sugestão recorrente entre as falas dos adolescentes entrevistados. Contudo, a organização do trabalho contemporânea, estabelecida sob a égide do sistema capitalista e suas políticas de gestão, dificulta o fortalecimento do coletivo dos trabalhadores contra situações abusivas. As mudanças sugeridas pelos jovens trabalhadores, embora pareçam de fácil aplicação, extrapolam o poder gerencial dos gestores inseridos na lógica do sistema e revelam a necessidade de uma mudança estrutural profunda.

Heloani (2008) enfatiza que, ainda que seja importante a criação de um canal de denúncias pelo departamento de recursos humanos das empresas, só isso é insuficiente. A solução real estaria em humanizar o processo laboral, criando espaços de intervenção do coletivo e fortalecendo as relações de trabalho, espaço onde se aprende o exercício da democracia. Só através do coletivo é possível atingir a saúde mental individual. Dessa forma, o trabalho pode tanto nos ajudar na constituição de uma identidade emancipatória, quanto induzir à construção de uma identidade deteriorada, que seria fonte de desestabilização e de sofrimento. Segundo Gaulejac (2007), é através do coletivo que o trabalho adquire sentido, que a aprendizagem se faz possível, que os comportamentos desviantes e os julgamentos arbitrários são reprimidos, permitindo que cada um se situe em relação aos outros e construa uma escala de valores entre o prescrito e o real, entre conteúdo e finalidades do trabalho. O autor relaciona o aumento das doenças profissionais, o sofrimento psíquico, a precarização e a insegurança social à degradação das condições de trabalho pela desagregação dos coletivos.

Como contribuição, ao pensarmos em "estratégias de enfrentamento" viáveis que poderiam ser incorporadas aos programas de educação para o trabalho de órgãos governamentais e não governamentais, como também em empresas, relembramos dois conceitos importantes quando se fala em promoção da saúde: empoderamento e autonomia.

Westphal (2009) destaca que o empoderamento está intrinsecamente ligado à participação social, na medida em que as pessoas devem poder assumir o controle sobre os determinantes da saúde e, a partir de ações motivadoras do empoderamento coletivo, participar dos processos de tomada de decisão. Ressalta-se que são consideradas como determinantes da saúde as condições biológicas, políticas, econômicas e sociais que influenciam a saúde.

A autonomia é outro conceito fundamental para a promoção da saúde. Segundo Onocko Campos e Campos (2009, p. 671), a autonomia é construída nas relações interpessoais por meio da dialética, sendo o sujeito autônomo corresponsável tanto pela constituição de si quanto do mundo que o cerca. Os autores destacam que para que a autonomia se efetive o sujeito deve ser capaz de lidar com o "[...] sistema de poder, de operar com conflitos e de estabelecer compromissos e contratos com outros sujeitos para criar bem-estar e contexto mais democráticos."

Nesse sentido, os trabalhadores devem ter acesso ao conhecimento dos possíveis fatores psicossociais relacionados ao trabalho que podem afetar a saúde física e mental. Enquanto pouco se fala aos trabalhadores sobre a saúde mental, estes deveriam também ter espaços de discussão sobre a promoção da saúde mental no trabalho, para que pudessem refletir em conjunto e contribuir com suas ideias e iniciativas a serem efetivadas na organização do trabalho. Os trabalhadores devem ser protagonistas na promoção da saúde mental no trabalho, não apenas na teoria, mas em seu fazer cotidiano. Embora o conceito de promoção da saúde comporte a compreensão de integralidade da saúde humana, as referências feitas a ela no campo da Saúde do Trabalhador costumam priorizar os aspectos físicos e colocar em segundo plano a saúde mental (BORSOI, 2007). Por essa razão, importa destacar a necessidade de promoção da "saúde mental" no trabalho, para que ganhem visibilidade e viabilidade tais ações no ambiente laboral.

Em nosso estudo foi possível perceber que os jovens que tinham mais conhecimento da lei e dos limites das relações interpessoais no ambiente de trabalho, portanto mais empoderados e autônomos, conseguiram enfrentar com mais firmeza situações abusivas, fossem elas por parte de colegas de trabalho ou de superiores hierárquicos. O empoderamento está relacionado ainda ao pertencimento a uma rede que fornece apoio social. Segundo Andrade e Vaitsman (2002, p. 928), o empoderamento emerge na interação com outros sujeitos,

\section{[...] gerando pensamento crítico em relação à reali- dade, favorecendo a construção da capacidade so- cial e pessoal e possibilitando a transformação de relações de poder. No nível individual, refere-se à habilidade das pessoas em ganhar conhecimento e controle sobre forças pessoais, sociais, econômicas e políticas para agir na direção da melhoria de sua situação de vida.}

Os achados dessa pesquisa vão ao encontro da discussão feita por Harvey, Blouin e Stout (2006) a respeito da função da personalidade proativa de adolescentes trabalhadores como moderadora dos efeitos dos conflitos interpessoais no trabalho em relação ao estresse psicológico e ao desempenho escolar. De acordo com os autores, a personalidade proativa é descrita como aquela a partir da qual os indivíduos não se deixam constranger por situações condicionantes, buscam oportunidades, mostram 
iniciativa, agem e perseveram para conseguir mudanças. Assim sendo, os indivíduos proativos seriam mais propensos a agir para lidar com conflitos e evitar que interferissem com suas vidas. A reflexividade é apontada por Gaulejac (2007) como essencial à construção do sujeito, contribuindo para que compreenda a si e ao mundo e seja capaz de se confrontar com a alteridade, se inserir em um coletivo e contribuir para o bem comum. Dessa forma, é possível relacionar o conhecimento à autonomia e ao empoderamento, na medida em que a personalidade proativa mediaria a busca por soluções alternativas aos conflitos interpessoais e, possivelmente, para o enfrentamento à violência psicológica no trabalho.

\section{Considerações finais}

As situações vivenciadas pelos jovens indicam que a saúde mental dos envolvidos pode estar em risco e que eles pouco conseguem fazer para enfrentar tais situações. Por outro lado, o apoio social é um mediador importante entre a violência psicológica no trabalho e a saúde mental dos trabalhadores, quando existem bons relacionamentos interpessoais. Muitos participantes, embora sendo alvo de situações de mal-estar, relataram ter boas interações pessoais no trabalho.

O chamado "mal-estar no trabalho" caracteriza-se por situações pontuais de violência psicológica, considerada "invisível” porque é difícil constatar sua ocorrência, inclusive dentre os envolvidos e, portanto, prová-la. Dessa maneira, os agredidos facilmente são vistos como exagerados ou simplesmente "aqueles que não sabem brincar”. Aí reside um ponto crucial de nossas considerações, as situações limítrofes, a linha tênue entre o inocente e o perverso, entre aquilo que faz bem (em que todo mundo participa e gosta de participar) e aquilo que faz mal (a diversão à custa do sofrimento alheio). Essas situações limítrofes tornam especialmente difíceis seu enfrentamento tanto por parte dos agredidos quanto por medidas administrativas. Entendemos que o grupo laboral dos adolescentes trabalhadores pode ser mais vulnerável à violência psicológica, embora talvez não existam diferenças significativas entre as situações que enfrentam e as vividas por outros profissionais. Talvez uma diferença a ser destacada sejam as "brincadeiras" que foram trazidas reiteradamente nas entrevistas, tanto como sinal de imaturidade na forma como percebem o ambiente profissional quanto como violência psicológica mascarada.

A condição socioeconômica dos participantes bem como a fase de aprendizado e, portanto, de inexperiência profissional na qual se encontravam podem também ter sido propiciadores das situações abusivas relatadas. Nesse sentido, algumas novas hipóteses poderiam ser estabelecidas e seriam necessárias novas investigações para verificar essas relações, como, por exemplo, que jovens de classe média estariam menos expostos ou sofreriam outros tipos de situações abusivas, ou, ainda, que jovens trabalhadores em geral percebem e relatam situações como sendo abusivas que trabalhadores com mais idade não identificariam dessa forma. Por outro lado, situações de desrespeito, de humilhação, de constrangimentos e de assédio sexual parecem estar banalizadas, naturalizadas e disseminadas em nossa sociedade, sendo "aceitas" como parte do ambiente profissional e também das relações sociais e familiares. Daí a importância de ações efetivas da Saúde Coletiva em conjunto com outros setores da sociedade, para que a violência psicológica deixe de ser um fenômeno invisível e gerador de sofrimento/adoecimento nas diversas instâncias sociais. O trabalho de enfrentamento a esse fenômeno pode e deve ser iniciado nos ambientes de trabalho. As ações e políticas públicas possíveis para a promoção da saúde mental no trabalho e prevenção da violência psicológica devem ser elaboradas de forma interdisciplinar, contando com a contribuição de diferentes áreas de conhecimento, como da Saúde do Trabalhador, da Psicologia Social e da Promoção da Saúde.

Neste estudo, percebemos que o acompanhamento profissional realizado pela ONG como parte dos requisitos de inserção de adolescentes no mercado de trabalho acaba sendo um espaço de "ouvidoria” dos acontecimentos no trabalho. É na ONG que os jovens encontram um espaço que lhes permite falar sobre sua vivência no trabalho, dúvidas, incertezas e maneiras de lidar com o cotidiano do trabalho. Contudo, inúmeros jovens ingressam no mercado de trabalho sem terem nenhum tipo de acompanhamento profissional, estes acabam não recorrendo a ninguém em situações abusivas, além de não terem acesso a informações importantes sobre saúde no trabalho.

O empoderamento dos adolescentes deve compreender não só as informações transmitidas aos jovens na sala de aula, discussões entre pares e troca de experiências, como também as interações com as coordenações dos programas aos quais atendem semanalmente ou mensalmente, bem como a participação em reuniões informais e formais entre gestores das empresas e coordenadores de programas de educação para o trabalho. Esse conjunto de ações poderia, entre outros, corrigir rumos que levassem a um tratamento dos jovens com equidade e a um real aproveitamento pelos aprendizes e estagiários de sua nova situação de trabalho em que novos saberes, práticas e experiências em áreas de seu interesse sejam de fato alcançados. Deveriam também ser incluídos temas de Saúde Mental e Trabalho, não só em organizações de educação e capacitação para o trabalho, mas também no ensino médio. Entre os temas, poderiam ser abordados: formas de violência presentes no trabalho; consequências da violência para a saúde; formas de enfrentamento com destaque para leis específicas e estratégias coletivas, além de serem exploradas as iniciativas imaginadas pelos adolescentes, incentivando-os ao debate e à reflexão. 


\section{Agradecimentos}

Os autores agradecem aos gestores da Organização Não Governamental que oferece cursos de aprendizagem no trabalho e que deu apoio durante a realização deste estudo, e aos jovens participantes deste estudo.

\section{Contribuições de autoria}

Turte-Cavadinha, S. L.: concebeu e desenvolveu o projeto de pesquisa. Fischer, F. M.: orientou a concepção e o desenvolvimento do projeto de pesquisa. Luz, A. A.: colaborou no delineamento, no levantamento e na interpretação dos dados. Turte-Cavadinha, E.: colaborou na análise, interpretação e discussão dos dados. Todos os autores trabalharam igualmente na concepção do artigo, na elaboração do texto e em sua revisão final.

\section{Referências}

AGÊNCIA EUROPÉIA PARA A SEGURANÇA E A SAÚDE NO TRABALHO - OSHA. Jovens trabalhadores - Factos e números: Exposição a riscos profissionais e consequências para a saúde, 2006. (Factsheet, n. 70). Disponível em: <https://osha. europa.eu/pt/publications/factsheets/70>. Acesso em: 08 out. 2011.

ANDRADE, G. R. B.; VAITSMAN, J. Apoio social e redes: conectando solidariedade e saúde. Ciência \& Saúde Coletiva, Rio de Janeiro, v. 7, n. 4, p. 925-934, 2002. http://dx.doi.org/10.1590/S141381232002000400023.

ANTUNES, C.; FONTAINE, A. M. Relação entre o conceito de si próprio e a percepção social na adolescência. Cadernos de Consulta Psicológica, n. 12, p. 81-92, 1996.

ASMUS, C. I. et al. Atenção integral à saúde de adolescentes em situação de trabalho: lições aprendidas. Ciência \& Saúde Coletiva, Rio de Janeiro, v. 10 , n. 4, p. 953-960, 2005. http://dx.doi.org/10.1590/ S1413-81232005000400018.

BARRETO, M. Violência, saúde e trabalho: uma jornada de humilhações. São Paulo: EDUC, 2003.

BORSOI, I. C. F. Da relação entre trabalho e saúde à relação entre trabalho e saúde mental. Psicologia \& Sociedade, Porto Alegre, v. 19, p. 103-111, 2007. Número especial. http://dx.doi.org/10.1590/S010271822007000400014.

BRASIL. Lei n 11.340, de 7 de agosto de 2006. Cria mecanismos para coibir a violência doméstica e familiar contra a mulher. Diá rio Oficial da República Federativa do Brasil. Brasília, DF, 7 ago. 2006. Disponível em: <http://www.planalto.gov. br/ccivil_03/_ato2004-2006/2006/lei/l11340.htm>. Acesso em: 18 jul. 2011.

BRASIL. Lei no 10.097, de 19 de dezembro de 2000. Altera dispositivos da Consolidação das Leis do Trabalho - CLT, aprovada pelo Decreto-Lei no 5.452, de 10 de maio de 1943.Diário Oficial da República Federativa do Brasil 19 dez 2000. Disponível em: <http://www.planalto.gov.br/ccivil_03/leis/110097. htm>. Acesso em: 09 dez. 2014.

BRASIL. Estatuto da criança e do adolescente: Lei $n^{\mathrm{o}}$ 8.069, de 13 de julho de 1990. 7. ed. Brasília: Edições Câmara, 2010. (Série legislação, n. 25).

CALDAS, L. P.; NEVES, F. Estratégias de enfrentamento em vivências de assédio moral no trabalho. In: SOBOLL, L. A. P. (Orgs.). Violência psicológica e assédio moral no trabalho: pesquisas brasileiras. São Paulo: Casa do Psicólogo, 2008. p. 135-163.

CHAUI, M. Ética e violência. Teoria e Debate, São Paulo, v. 11, n. 39, p. 32-41, 1998.

CORTINA, L. M. et al. Incivility in the workplace: incidence and impact. Journal of Occupational Health Psychology, v. 6, n. 1, p. 64-80, 2001. http://dx.doi. org/10.1037/1076-8998.6.1.64. PMid:11199258

DENZIN, N. K.; LINCOLN, Y. S. Handbook of qualitative research. 2. ed. Thousand Oaks, CA: SAGE, 2000.

FINERAN, S. Adolescents at work: gender issues and sexual harassment. Violence Against Women, v. 8, n. 8, p. 953-967, 2002. http://dx.doi. org/10.1177/107780102400447087.

FISCHER, F. M. et al. Occupational accidents among middle and high school students of the state of São Paulo, Brazil. Revista de Saude Publica, v. 37, n. 3, p. 351-356, 2003. http://dx.doi.org/10.1590/S003489102003000300014. PMid:12792687

FREITAS, M. E.; HELOANI, J. R.; BARRETO, M. Assédio moral no trabalho. São Paulo: Ed. Cengage, 2008.

FRIGOTTO, G. Juventude, trabalho e educação no Brasil: perplexidades, desafios e perspectivas. In: NOVAES, R.; VANNUCHI, P. (Orgs.). Juventude e sociedade: trabalho, educação, cultura e participação. São Paulo: Fundação Perseu Abramo, 2004. p. 180216. 
FRONE, M. R. Interpersonal conflict at work and psychological outcomes: testing a model among young workers. Journal of Occupational Health Psychology, v. 5, n. 2, p. 246-255, 2000. http://dx.doi. org/10.1037/1076-8998.5.2.246. PMid:10784288

GARVER, N. What violence is. In: BIERMAN, A. K.; GOULD, J. A. (Eds.). Philosophy for a new generation. 2. ed. New York: Macmillan, 1973. p. 256-266.

GAULEJAC, V. Gestão como doença social: ideologia, poder gerencialista e fragmentação social. Aparecida, SP: Ideias e Letras, 2007.

GOSDAL, T. C.; SOBOLL, L. A. P. (Orgs.). Assédio moral interpessoal e organizacional: um enfoque interdisciplinar. São Paulo: LTr, 2009.

HARVEY, S.; BLOUIN, C.; STOUT, D. Proactive personality as a moderator of outcomes for young workers experiencing conflict at work. Personality and Individual Differences, v. 40, n. 5, p. 1063-1074, 2006. http://dx.doi.org/10.1016/j.paid.2005.09.021.

HELOANI, R. Assédio moral: a dignidade violada. Aletheia, Canoas, n. 22, p. 101-108, 2005.

HELOANI, J. R. Contribuições da psicologia do trabalho em casos de assédio moral. In: SOBOLL, L. A. P. (Org.). Violência psicológica no trabalho e assédio moral: pesquisas brasileiras. São Paulo: Casa do Psicólogo, 2008. p. 95-104.

HELOANI, J. R. M.; BARRETO, M. M. S. Aspectos do trabalho relacionados à saúde mental: assédio moral e violência psicológica. In: GLINA, D. M. R.; ROCHA, L. E. (Orgs.). Saúde mental no trabalho. Da teoria a prática. São Paulo: Rocca, 2010. p. 31-48.

HIRIGOYEN, M. F. Mal estar no trabalho: redefinindo o assédio moral. 3. ed. Rio de Janeiro: Editora Bertrand Brasil, 2006.

INTERNATIONAL LABOUR OFFICE - ILO. Safe work bookshelf. Geneva, 2006.

INTERNATIONAL LABOUR ORGANIZATION ILO. Decent work and youth in Latin America, 2010, 27 Oct. 2010. Disponível em: < http://www.ilo.org/ employment/Whatwedo/Publications/WCMS 146296/ lang--en/index.htm>. Acesso em: 08 out. $201 \overline{1}$.

JACKSON, M.; ASHLEY, D. Physical and psychological violence in Jamaica's health sector. Revista Panamericana de Salud Pública, Washington, v. 18, n. 2, p. 114-121, 2005. http://dx.doi.org/10.1590/ S1020-49892005000700006. PMid:16156962

LAPERRIÈRE, A. A teorização enraizada (grounded theory): procedimento analítico e comparação com outras abordagens similares. In: POUPART, J. et al. (Orgs.). A pesquisa qualitativa: enfoques epistemológicos e metodológicos. Petrópolis: Vozes, 2008. p. 353-385.

LUNARDI FILHO, W. D.; LUNARDI, V. L.; SPRICIGO, J. O trabalho da enfermagem e a produção da subjetividade de seus trabalhadores. Revista LatinoAmericana de Enfermagem, v. 9, n. 2, p. 91-96, 2001. http://dx.doi.org/10.1590/S0104-11692001000200013. PMid:12040808

MARTINS, J. C. O.; ROCHA, L. A.; NASCIMENTO, D. C. Assédio moral: uma prática perversa no ambiente de trabalho. Revista Humanidades, Fortaleza, v. 24, n. 1, p. 11-20, 2009.

MCLAUGHLIN, H.; UGGEN, C.; BLACKSTONE, A. Social class and workplace harassment during the transition to adulthood. In: MORTIMER, J. T. (Ed.). Social class and transitions to adulthood. 1. ed. Hoboken, NJ: Wiley Periodicals Inc., 2008. p. 85-98. (New Directions for Child and Adolescent Development, n. 119. The Jossey-Bass Education Series).

MINAYO, M. C. S. O desafio do conhecimento: pesquisa qualitativa em saúde. 11. ed. São Paulo: Hucitec, 2008.

MINAYO-GOMEZ, C.; MEIRELLES, Z. Crianças e adolescentes trabalhadores: um compromisso para a saúde coletiva. Cadernos de Saúde Pública, Rio de Janeiro, v. 13, n. 2, p. 1-10, 1997.

OLIVEIRA, R. P.; NUNES, M. O. Violência relacionada ao trabalho: uma proposta conceitual. Saúde e Sociedade, v. 17, n. 4, p. 22-34, 2008. http://dx.doi. org/10.1590/S0104-12902008000400004.

ONOCKO CAMPOS, R. T.; CAMPOS, G. W. S. Coconstrução de autonomia: o sujeito em questão. In: CAMPOS, G.W. S. et al. (Orgs.). Tratado de saúde coletiva. São Paulo: Hucitec, 2009. p. 669-688.

ORGANIZAÇÃO INTERNACIONAL DO TRABALHO - OIT. Trabalho decente e juventude no Brasil. Brasília, 2009.

RAUSCHER, K. J. Workplace violence against adolescent workers in the US. American Journal of Industrial Medicine, v. 51, n. 7, p. 539-544, 2008. http://dx.doi.org/10.1002/ajim.20590. PMid:18491372

RODRIGUES, R. R. J.; IMAI, R. Y.; FERREIRA, W. F. Um espaço para o desenvolvimento interpessoal no trabalho. Psicologia em Estudo, Maringá, v. 6, n. 2, p. 123-127, 2001.

ROSPENDA, K. M.; RICHMAN, J. A.; SHANNON, C. A. Prevalence and mental health correlates of harassment and discrimination in the workplace: results from a national study. Journal of Interpersonal Violence, v. 24, n. 5, p. 819-843, 2009. http://dx.doi. org/10.1177/0886260508317182. PMid:18463311

SAITO, M. I. Violência interpessoal na adolescência. In: WESTPHAL, M. F.; BYDLOWSKI, C. R. (Eds.). Violência e juventude. São Paulo: Hucitec, 2010.

SALADINI, A. P. S. Trabalho, medo e sofrimento: considerações acerca do assédio moral. Revista Jurídica Unifil, v. IV, n. 4, p. 13-24, 2007. 
SAWAIA, B. B. As artimanhas da exclusão: análise psicossocial e ética da desigualdade social. Petrópolis: Editora Vozes, 2001.

SILVA, L. L.; COELHO, E. B. S.; CAPONI, S. N. C. Violência silenciosa: violência psicológica como condição da violência física doméstica. Interface Comunicação, Saúde, Educação. Botucatu, v. 11, n. 21, p. 93-103, 2007. http://dx.doi.org/10.1590/S141432832007000100009 .

SIQUEIRA, M. M. M.; PADOVAM, V. A. R. Bases teóricas de bem-estar subjetivo, bem-estar psicológico e bem-estar no trabalho. Psicologia: Teoria e Pesquisa, Brasília, v. 24, n. 2, p. 201-209, 2008. http://dx.doi. org/10.1590/S0102-37722008000200010.
TOLFO, S. R.; PICCININI, V. Sentidos e significados do trabalho: explorando conceitos, variáveis e estudos empíricos brasileiros. Psicologia \& Sociedade, Porto Alegre, v. 19, p. 38-46, 2007. Número especial. http:// dx.doi.org/10.1590/S0102-71822007000400007.

WAGNER, L. R., et al. Relações interpessoais no trabalho: percepção de técnicos e auxiliares de enfermagem. Cogitare Enfermagem, v. 14, n. 1, p. 107113, 2009.

WESTPHAL, M. F. Promoção da saúde e prevenção de doenças. In: CAMPOS, G. W. S. et al. (Orgs.). Tratado de saúde coletiva. São Paulo: Hucitec, 2009. p. 635667. 